\title{
La escritura testimonial en las trayectorias intelectuales de Rodolfo Walsh y Francisco Urondo: experiencias estético-políticas en tiempos de revuelta
}

Testimonial writing in Rodolfo Walsh and Francisco Urondo: political-aesthetical experiences in revolutionary times

\section{FABIANA GRASSELLI}

INCIHUSA-CONICET·fgrasselli@mendoza-conicet.gob.ar

Profesora e investigadora en el Instituto de Ciencias Humanas Sociales y Ambientales y en CONICET. Trabaja como docente adscripta en la Facultad de Ciencias Políticas y Sociales de la UNCUyo. Forma y ha formado parte de equipos de investigación sobre temas de género, política y memoria. Sus intereses giran en torno a la historia del campo literario argentino de las décadas del sesenta y setenta, las relaciones entre prácticas literarias y prácticas políticas y la literatura testimonial. Es autora del libro Rodolfo Walsh y Francisco Urondo: el oficio de escribir.

Resumen: Este trabajo se ocupa de las trayectorias políticas e intelectuales de Rodolfo Walsh y Francisco Urondo desde una perspectiva que atiende a mostrar y analizar los singulares puntos de contacto entre sus recorridos en lo que respecta a una cuestión central en las polémicas culturales de los años sesenta y setenta en América Latina: las búsquedas tendientes a subvertir los modos de concebir las relaciones entre arte, política y sociedad.La investigación focaliza en los posicionamientos estético-políticos de Walsh y Urondo en un momento considerado como un clivaje dentro de la historia intectual argentina: los finales de la década del sesenta. Se abordan los entrecruzamientos de sus proyectos escriturales y sus declaraciones programáticas en torno a la escritura testimonial, explorando las modos en que precipitan en ella las experiencias vinculadas a su oficio de escritores y militantes.

Palabras clave: Walsh, Urondo, testimonio, política.

\begin{abstract}
This paper deals with the political and intellectual trajectories of Rodolfo Walsh and Francisco Urondo from a perspective focusing in display and analyze the singular points of contact between their pathways regarding a central issue in cultural debates of the sixties and seventy in Latin America: the quests aiming to subvert how the relationship among art, politics and society are conceived. The research focuses on the aesthetic and political positions of Walsh and Urondo in a moment considered as an inflection point within the Argentinean intectual history: the end of the sixties. The crossovers of their writing projects and programmatic statements about the testimonial writing are addressed, exploring how the experiences related to their work as writer and militants precipitate on it.
\end{abstract}

Key words: Walsh, Urondo, Testimony, Politics. 
Los caminos del compromiso político de Paco y Rodolfo no fueron los mismos pero siempre se encontraron en las coyunturas esenciales. En la relación entre Paco y Rodolfo había un cierto paralelismo en cuanto a iniciativas y proyectos. Lilia Ferreyra

La literatura está hecha para que la protesta humana sobreviva al naufragio de los destinos individuales.

Jean-Paul Sartre

\section{Introducción}

Rodolfo Walsh y Francisco Urondo hacen sus primeras intervenciones en el terreno del quehacer cultural y el campo literario argentino ni bien comenzada la década del cincuenta; y despliegan su producción como artistas, periodistas e intelectuales, y su tarea como militantes, a lo largo de los años cincuenta, sesenta y los primeros setenta, hasta que la dictadura de 1976 cercena sus vidas y silencia sus trabajos ${ }^{1}$.

Los dos escritores no sólo coinciden en el período de poco más de veinticinco años en que desarrollan su labor literaria y periodística, y en algunos rasgos biográficos significativos, sino que también se anudan entre ellos, fundamentalmente desde 1968, coincidencias y fraternidades. Éstas comprenden vínculos de amistad, opciones ideológicas, espacios de militancia, así como cercanías en sus búsquedas de una práctica intelectual encarnada como respuesta contrahegemónica a lo que fue percibido como una crisis de la cultura burguesa, en una situación histórica cuyo perfil se configura en torno a la noción de cambio radical (Gilly, 1985; Pucciarelli, 1999; Izaguirre, 2009; Gilman, 2003).

El final de la década del sesenta fue un tiempo de una densidad singular, cuya marca fundamental fue una experiencia del mundo caracterizada por la visión compartida de que era necesario y posible, dicho en términos de la época, revolucionar el orden establecido. En ese horizonte histórico, condensan las configuraciones y experiencias de un campo cultural latinoamericano y argentino radicalizado, en el que la importancia política concedida al intelectual, al artista y a sus producciones específicas estuvo acompañada de una interrogación permanente por su legitimidad social y por la intensa voluntad de crear un arte político y revolucionario. Este es el terreno en el que los escritores-intelectuales Rodolfo Walsh y

\footnotetext{
${ }^{1}$ Ambos pertenecen a la misma generación, pues Walsh nace en Choele Choel, Río Negro, un 9 de enero de 1927 y Urondo, tres años más tarde, en la capital de Santa Fe, el 10 de enero de 1930. Sus violentas muertes a manos de las fuerzas represivas del terrorismo de Estado también se asemejan. Walsh es secuestrado y desaparecido el 25 de marzo de 1977, al día siguiente de haber distribuido la Carta abierta de un escritor a la Junta Militar; y Urondo moría en combate algunos meses antes en Mendoza, en junio de 1976.
} 
Francisco Urondo desarrollan sus trayectorias, singulares y a la vez confluyentes, desplegando sus proyectos escriturales al interior de las formaciones culturales de la época.

Esos anudamientos en las trayectorias walshiana y urondiana sostuvieron mi interés en construir un abordaje conjunto e interrelacionado de los itinerarios de ambos autores, puesto que me permitieron visibilizar que hacia fines de los sesenta articulan lo que podría conceptualizarse como un programa estético-político en el cual, aunque siempre en tensión y con un carácter en cierto modo provisorio, la escritura testimonial constituye una estrategia privilegiada. En otras palabras, la opción por un proyecto literario con una gravitación decisiva de la escritura testimonial constituye una suerte de intentona por parte de Walsh y Urondo de abolir la brecha entre la práctica literaria, con sus posibilidades de ejercicio abiertas en el marco del desarrollo histórico de las instituciones y formaciones culturales de las coordenadas históricas de los sesenta-setenta, y la práctica política asumida en términos de transformación de la sociedad, la cual también fue habilitada como posibilidad a partir de los procesos de radicalización política que caracterizaron al periodo. El trabajo con la escritura testimonial de Walsh y Urondo es propuesto por ellos como una estrategia estético-política, en el juego de límites y presiones que se configura en esa singular coyuntura de condensación histórica. En este sentido, la praxis escritural desplegada por los autores bajo las condiciones específicas de las formaciones sociales y culturales de esos años, dio lugar a experiencias transitadas como parte de la construcción de su oficio de escritores políticos que entraron en contradicción con las fronteras establecidas por la institución literaria hegemónica.

Esta hipótesis, una de las posibles puertas de entrada a los itinerarios y producciones de Walsh y Urondo, supone una decisión interpretativa, la de privilegiar el tramo de sus trayectorias en que precipita una opción por un cierto tipo de escritura que, desde la perspectiva de estos escritores, aparecía como la vía a través de la cual producir un vínculo entre arte y política capaz de mantenerlos en tenso diálogo. En tal sentido, se ha puesto el énfasis en un momento de sus itinerarios, el momento que se inaugura en los años 1968-1969, que se ha juzgado clave après coup, es decir, a partir de la ventaja hermenéutica que significa situarse en el presente y desde allí mirar hacia el pasado retrospectivamente, para dar forma al relato de dichas biografías intelectuales. Es la mirada desde el "ahora" la que nos ha permitido visualizar en los años 1968-1969 un hito significativo que orientaría los recorridos posteriores y confluyentes de Walsh y Urondo, y que ha posibilitado vincular sus modos de transitar, a través de lo testimonial, la pregunta por las relaciones entre arte y política, por el lugar de los intelectuales en la revolución.

\section{Trayectorias singulares y convergentes en el escenario de un momento de radicalización}

Las trayectorias de Rodolfo Walsh y Francisco Urondo comienzan a ponerse en contacto en el tiempo cercano al año 1968. Hasta ese momento sus itinerarios transcurren de modo paralelo, aunque 
participan en redes de intelectuales con múltiples intersecciones y convergen en espacios periodísticos como las revistas culturales argentinas Leoplán y Panorama (Baschetti, 1994; Jozami, 2006; Redondo, 2001; Redondo, 2005; Gerbaudo y Falchini, 2009) y la agencia latinoamericana de noticias Prensa Latina, surgida en el marco de la Revolución Cubana y animada por el periodista argentino Jorge Ricardo Masetti. Asimismo ocupan posiciones dentro del campo intelectual argentino y latinoamericano que se revelan cercanas porque suponen ciertas coincidencias en lo relativo a tres aspectos: la pertenencia ideológica, los modos de elaborar las experiencias políticas vividas en un país asediado por las crisis institucionales luego de 1955 y la presencia de ciertas preocupaciones respecto del lugar que le corresponde a la práctica simbólica en esas singularísimas coordenadas que constituyen los años sesenta en Latinoamérica. En cuanto a las afinidades ideológicas, ambos aparecen vinculados ideológicamente al progresismo y la izquierda (antiimperialismo, desarrollismo, colaboración con movimientos revolucionarios y de liberación latinoamericanos). Atraviesan de modo similar, aunque con matices y particularidades, experiencias como: el antiperonismo de las formaciones culturales izquierdistas en los cincuenta -que se diferenciaron del antiperonismo liberal-, el apoyo, en un primer momento, y luego el repudio, a la autodenominada Revolución Libertadora, el desencanto frente al proyecto frondizista y la participación, en tanto escritores y periodistas, en el proceso de la Revolución Cubana y en organizaciones que se ubican dentro de lo que ha sido conceptualizado como la nueva izquierda de esos años (Redondo, 2005a).

El tránsito de las trayectorias de Walsh y Urondo por este devenir histórico de la sociedad argentina tiene la impronta de procesos sociales, políticos y culturales cuyas notas principales podrían pensarse, en términos gramscianos, como el desarrollo de una crisis de hegemonía que venía gestándose desde fines de los cincuenta (Gilly, 1985). Las tensiones generadas por las cambios asociados a la apertura liberal de la economía y a la restricción de las conquistas obreras, impulsados por gobiernos democráticos y autoritarios luego de 1955, se intensificaron durante la dictadura de Onganía. En ese marco de transformaciones económicas, de proscripción del justicialismo y de creciente autoritarismo y clima represivo se abrió un ciclo, a partir de 1966, en el que es posible identificar una intensa actividad política, auge de masas, y el crecimiento de la izquierda marxista y peronista. En dicho clima de efervescencia social, se desarrolló un sindicalismo de gran combatividad -la CGT de los Argentinos constituyó una experiencia de importante gravitación en ese terreno-, crecieron grupos y organizaciones de la nueva izquierda que se desarrollaban por dentro y por fuera del movimiento peronista, planteaban sus demandas bajo las consignas de "liberación nacional", "socialismo" y "revolución”, e involucraban no sólo a la clase obrera sino también a importantes franjas de los sectores medios, como estudiantes e intelectuales. Las fuerzas sociales emergentes se manifestaron tanto en levantamientos urbanos, cuyo 
punto de mayor ascenso en las luchas fue el Cordobazo (1969), como en la revuelta cultural, y en la militancia política tanto como en el accionar guerrillero (Tortti, 1999; Pozzi, 2004).

Al ritmo de esos procesos, las formaciones culturales en las que se inscriben Walsh y Urondo, que estaban vinculadas al pensamiento de esta izquierda heterodoxa y venían sosteniendo arduos debates en torno a la figura del intelectual y su responsabilidad política, se unificaron en un mismo lugar de oposición junto con aquellos sectores sociales y organizaciones políticas que asumieron su enfrentamiento al régimen militar, lo cual tuvo el efecto de un poderoso revulsivo. Muestra de ello son las experiencias y acontecimientos ocurridos en un marco de confluencia entre núcleos de intelectuales y sectores obreros que se ligaron a la CGT de los Argentinos, como la muestra Tucumán Arde², el grupo Cine Liberación animado por Fernando Solanas y Octavio Getino, el propio Semanario CGT dirigido por Rodolfo Walsh, la producción gráfica y muralística de Ricardo Carpani. En ellas se expresa una voluntad representativa de una amplia franja del campo intelectual argentino, que hacia fines de los sesenta intenta vincularse a la clase obrera en tanto sujeto de la revolución (Mestman, 1997: 207). En este proceso, el acontecimiento que funcionó "como decisivo vector de radicalización de los intelectuales" (Tortti, 1999) fue el Cordobazo, en mayo de 1969. La presencia de obreros al lado de los estudiantes en las calles de Córdoba transformó radicalmente el horizonte político, seccionando el espacio cultural. Se trató de una "sorpresa gigantesca", no prevista ni en los cálculos del poder ni en los de la oposición; un acontecimiento, que venía a probar que algo diferente y nuevo era posible en Argentina, y que reorientó la mirada y la intervención de intelectuales y productores culturales hacia una articulación práctica con el movimiento obrero o la protesta social.

Así, es posible afirmar, recuperando los trabajos de varios especialistas en el período (Longoni y Mestman, 2000; Gilman, 2003; de Diego, 2003; Tortti, 1999; Terán, 1993), que 1968 y 1969 son dos años de acontecimientos decisivos para la intelectualidad de izquierda nacional y continental (en el ámbito latinoamericano son considerados como parteaguas el denominado "Caso Padilla" y el Congreso Cultural de La Habana, en 1968) y constituyen el momento en el que se visualiza el enfrentamiento entre las dos tendencias clave del campo intelectual argentino y latinoamericano: el "horizonte modernizador" y el "horizonte revolucionario" (Longoni y Mestman, 2000: 15). El desarrollo de experiencias

\footnotetext{
${ }^{2}$ En palabras de Pablo Renzi: “ “Tucumán Arde’ fue una obra de concepción y realización colectiva y multidisciplinaria que se montó en noviembre de 1968 en las sedes de la "CGT de los Argentinos" de Rosario y Buenos Aires. La hicieron intelectuales y artistas de diferentes disciplinas, de ambas ciudades, que se proponían crear un fenómeno cultural de características políticas que excediera los cauces habituales de las vanguardias que ellos mismos practicaban. Para ello era necesario asimilar el concepto de vanguardia estética al de vanguardia política. Un objetivo fue el de evitar la "absorción de la obra" arrancándola del circuito tradicional de las instituciones culturales oficiales; el otro, transformar el hecho en un medio de transformación política y de adhesión a las luchas populares del momento. El tema Tucumán, y los problemas sufridos por los cañeros y los obreros de los ingenios tucumanos, era uno de los cinco puntos del plan de lucha de la CGT, que los artistas apoyaron”.
} 
político-culturales decisivas para los procesos del espacio cultural, la radicalización de las prácticas estéticas, la mutua reterritorialización de lo político y lo cultural, el ascenso de la protesta social y la crisis de hegemonía del régimen hablan de correspondencias por demás significativas entre las dinámicas social, política y cultural. Así, los años 1968 y 1969 aparecen, desde diversas miradas y aproximaciones, como una coyuntura de máxima tensión, como un hito que permite observar la posterior profundización de la radicalización del campo intelectual y una tendencia al borramiento de los límites entre práctica política y práctica intelectual.

En este momento histórico denso, los hilos de las trayectorias de Rodolfo Walsh y Francisco Urondo se entrelazan y también dan cuenta de un punto de inflexión, evidenciando las marcas de una dialéctica entre itinerario biográfico y proceso histórico. Retomando las conceptualizaciones de Franco Ferrarotti (1990) podríamos decir que sus biografías intelectuales constituyen un material que totaliza el sistema social; son la sedimentación de lo vivido en la historia. Una lectura atenta a la relación entre historias subjetivas y procesos históricos colectivos habilita una clave de desciframiento de las decisiones personales de estos autores, sus elecciones políticas y estéticas.

En este sentido, al hilvanar las experiencias estético-políticas de Walsh y Urondo se hacen visibles las marcas de las condiciones históricas en las que esas experiencias de construcción de su "oficio de escribir" emergen como un proceso complejo, "sobredeterminado" (Williams, 1980). El período que se abre a partir de 1968-1969, puede leerse como un clivaje en sus recorridos: en la vida política e intelectual aparecen recolocaciones y los proyectos escriturales son resignificados. Asimismo, los puntos de contacto y similitudes que se observan entre sus trayectorias durante los cincuenta y la primera mitad de los sesenta, se intensifican de modo muy marcado a partir de 1968, cuando aparecen entrelazamientos en sus actuaciones como intelectuales y militantes, y en sus programas de escritura.

Hacia fines de los sesenta, Rodolfo Walsh y Francisco Urondo han trazado un itinerario como escritores políticos que parece gravitar, de modo a veces más o menos acentuado, en torno a una pregunta crucial del campo intelectual de la época: ¿es posible una práctica artística que pueda configurarse como una práctica política emancipadora? Sus actuaciones y producciones de esos años previos a 1968 pueden leerse como continuos ensayos de respuesta a esa pregunta experimentados en el terreno de las condiciones efectivas en que ejercieron la escritura.

\subsection{Afinidades electivas y trayectos compartidos desde 1968}

Una mirada sobre el conjunto de prácticas intelectuales de nuestros escritores en la época previa a 1968, que considere las modulaciones en su trabajo con la escritura, sus posiciones en el campo literario, las configuraciones ideológicas y agencias que intervinieron en el desarrollo de sus "habitus" autoriza a comprender el curso de la construcción de su oficio de escribir en función de una experiencia 
Fabiana Grasselli. La escritura testimonial...

que aparece como rasgo articulador: el haber abarcado el ejercicio de la escritura literaria y periodística como actividades llevadas adelante en un proceso, tanto de tensión, como de mutua imbricación. Asimismo, dicho ejercicio de la escritura se despliega como elemento constitutivo/constituyente de un proceso histórico atravesado por una estructura del sentir: la idea, compartida por importantes fracciones sociales, acerca de la necesidad de una transformación revolucionaria. Esto implica, por una parte, que Urondo y Walsh, experimentaron la escritura como un oficio y un trabajo, inscribiéndose en una tradición de escritores argentinos que Rivera denomina "un tipo particular de escritor profesional, que en cierta medida estructurará su propio modelo y sus tablas de valores particulares, por lo común a espaldas de los modelos y códigos de los letrados del circuito ‘culto’ o ‘académico”’ (Rivera, 1998:13). Por otra parte, este rasgo compartido en sus trayectorias aparece vinculado a su praxis política. En otras palabras: su actividad intelectual estaría cada vez más marcada por la necesidad de dar un sentido emancipatorio a la práctica de la escritura. En ese sentido, a mediados de la década del sesenta, cuando sus textos literarios y periodísticos les generaban un importante reconocimiento, Rodolfo Walsh y Francisco Urondo se incorporaron al Movimiento de Liberación Nacional (MALENA) ${ }^{3}$. Su acercamiento a este agrupamiento político está signado por esa doble inscripción, intelectual y política, que caracteriza en esa época a los hombres y mujeres de la cultura.

Walsh, por su parte, se vincula a esta agrupación política a partir del contacto que había entablado con algunos integrantes de Contorno, por lo menos con Noé Jitrik, cuando buscó algún apoyo del frondizismo para la difusión de Operación Masacre y, más tarde, trabó una relación personal con los Viñas y otros de los contornistas que frecuentaban la librería de Jorge Álvarez (Jozami, 2004; Jozami 2006: 162-163). Urondo era amigo de Noé Jitrik y había compartido con él la experiencia de fundación y conformación del grupo Zona de la poesía americana, además de frecuentar, por esa época, el grupo de filosofía y teoría marxista que coordinaba León Rozitchner (Montanaro, 2003: 72-73). Tanto Walsh como Urondo aparecen, en 1968, integrando un Consejo de Redacción de la revista Problemas del Tercer Mundo, una iniciativa editorial de Ismael Viñas, en la que también participaban Roberto Cossa, Ricardo Piglia, Andrés Rivera, Jorge Rivera y León Rozitchner.

\footnotetext{
${ }^{3}$ Grupo político de la llamada Nueva Izquierda, encabezado por Ismael Viñas, y compuesto por militantes vinculados al Ejército de Liberación Nacional, otros provenientes del Partido Socialista, y representantes del peronismo de izquierda (Montanaro, 2003; Pacheco, 2010; Romano, 2002: 43; Jozami, 2006: 162). El MALENA, que había sido conformado a inicios de la década del sesenta, había roto totalmente con las políticas encarnadas por el frondizismo, había resuelto distanciarse del PCA y había estrechado lazos con la Revolución Cubana. Además, entre sus concepciones políticas estaba la idea de que la violencia era intrínseca al sistema y que sólo a partir de la lucha armada había posibilidades de tomar el poder, pero sostenía que las formas que adoptaran las organizaciones revolucionarias debían surgir de la estructura económica, política y social de cada región (Pacheco, 2010).
} 
El clima generado por esta militancia refuerza, tanto en Walsh como en Urondo, su apoyo a la causa cubana y su involucramiento en ese frente de intelectuales que conformó el proceso revolucionario. De hecho ambos viajan a Cuba a fines de 1967, en esta ocasión invitados a participar del Congreso Cultural de La Habana, al que concurrieron "medio millar de hombres de cultura, venidos de setenta países" (Casa de las Américas, 1968a: 3-4). El clima intelectual de la isla estaba signado por la reciente muerte del Che, lo cual se hizo patente en el número de Casa de las Américas inmediatamente posterior al asesinato de Ernesto Guevara. Dicho número está enteramente consagrado a "la situación del intelectual latinoamericano", como dando por sentado que homenajear al Che, "ejemplo de la más alta encarnación del intelectual y el combatiente”, implicaba también revisar las propias convicciones y actuaciones de los intelectuales, asumiendo su figura como parámetro (Gilman, 2003:204). Los debates desarrollados durante ese congreso testimonian la convergencia de dos concepciones antagónicas sobre la labor del intelectual que entrarán en conflicto: "se superponen allí disputas más o menos explícitas, pero también dos ideales, uno que está en curso de convertirse en residual, otro emergente que se tornará hegemónico" (Gilman, 2003:206). En este sentido, la resolución general del Congreso Cultural de La Habana, publicada en el número 47 de la revista Casa de las Américas, afirmaba que en una sociedad en revolución, "el intelectual está obligado a ser crítico de sí mismo y conciencia crítica de la sociedad”, no obstante, "eso no basta” puesto que la revolución promueve constantemente nuevas exigencias (Casa de las Américas, 1968b: 104-105). En consonancia con estas concepciones, se abre la declaración con una cita de Régis Debray: "el secreto del valor del intelectual no reside en lo que éste piensa, sino en la relación entre lo que piensa y hace", y a continuación se manifiesta que "defender la revolución es defender la cultura”, para finalmente agregar que el cambio sólo podía producirse a través de la lucha armada. Asimismo, se plantea que entre los insoslayables deberes del intelectual del Tercer Mundo, se postulan los de la lucha que comienza con la incorporación al combate por la independencia nacional, dado que, si la derrota del imperialismo es el prerrequisito inevitable para el logro de una auténtica cultura, "el hecho cultural por excelencia para un país subdesarrollado es la revolución" (Casa de las Américas, 1968b). Lo más importante era la afirmación de que sólo podría llamarse intelectual revolucionario aquel que estuviera dispuesto, no sólo a transformar el ejercicio del arte, la literatura y la ciencia en un arma de lucha, sino también a compartir las tareas combativas de su pueblo.

Además de estos espacios de confluencia, el parte aguas que fue 1968 se configuró como escenario de otros recorridos de significación superlativa para ambos escritores, que también resuenan entre sí.

En el caso de Walsh, al retorno de Cuba, luego de participar del Congreso Cultural de La Habana, visita la residencia de Perón en Madrid, donde conoce al dirigente gráfico Raimundo Ongaro. Éste le propone participar de lo que luego se llamará la CGT de los Argentinos, colaborando con la 
prensa sindical. Como es bien sabido ésta experiencia, con toda su complejidad y tensiones, resignificará sus tareas como intelectual militante. En 1969 publicará ¿Quién mató a Rosendo? Y participará de la elaboración del Programa del $1^{\circ}$ de mayo de la CGT de los Argentinos. Este proceso atravesado en el ámbito de la CGTA tiene la impronta de una tensión fundada, por una parte, sobre la convicción de estar asumiendo los compromisos intelectuales que los tiempos demandan, y por otra, sobre la conciencia de la crisis que esto supone para un trabajo literario tal como se concibe dentro de lo límites de la tradición hegemónica de la cultura dominante. Dicha tensión aparece tematizada en sus papeles personales y también públicamente, aunque es resuelta a través de la praxis derivada de sus decisiones políticas y del compromiso militante que ha asumido en los términos expresados en el Programa del $1^{\circ}$ de Mayo: su labor narrativa será subordinada a la escritura de lo "urgente", si bien sus proyectos literarios estarán presentes hasta el último de sus días. En este derrotero político-intelectual, en 1969 se incorporará al Peronismo de Base, que representaba una experiencia de proyecto autónomo socialista en el movimiento de los trabajadores. A partir de 1970, Rodolfo Walsh se incorporará a las Fuerzas Armadas Peronistas (FAP) que habían surgido de manera casi coincidente con la CGT de los Argentinos y en las que también militan Raimundo Ongaro y varios dirigentes de base combativos provenientes del peronismo, como Raimundo Villaflor. Más tarde este proceso desembocará en la militancia en Montoneros.

En un recorrido equivalente al de Walsh, de franca radicalización e involucramiento en las luchas populares, Francisco Urondo se vincula en 1968 a las FAR, cuando conoce a Carlos Olmedo a través de su hija, Claudia Urondo, y asume integralmente la militancia política. Más tarde, en 1973 las FAR se fusionarán con Montoneros, bajo el nombre de ésta última agrupación. Asimismo, la producción literaria y periodística que Urondo despliega en ese tiempo, sigue esa línea de marcada politización. En 1968 publica el poema Adolecer por Editorial Sudamericana, escrito entre 1965 y 1967. Este poema "marca una transición en la biografía intelectual y política del poeta en tanto expresa, por un lado, su conversión de poeta en un sujeto revolucionario y, por el otro, una intensificación en los modos de la intertextualidad y el discurso indirecto como forma plena de la escritura" (Redondo, 2005: 116). Ese mismo año, publica, a través de la editorial Galerna, el ensayo Veinte años de poesía argentina 1940-1960, donde analiza los movimientos mediante una mirada que anuda la historia literaria con la coyuntura política y los procesos sociales atravesados por el país.

En 1969, Walsh y Urondo vuelven a confluir en Cuba para formar parte de los jurados para los concursos literarios que organiza Casa de las Américas. El poeta uruguayo Mario Benedetti, quien reside en La Habana desde noviembre de 1967 y dirige el Centro de Investigaciones Literarias de Casa de las Américas, aprovecha la estadía de nuestros escritores y de Juan Carlos Portantiero, para organizar una mesa de debate cuyo tema central es La literatura argentina del siglo $X X$. En este intercambio, 
Urondo delimita la fracción del campo intelectual identificada con el "oficialismo literario", señalando que, desde 1943, la posición dominante dentro del campo la detenta el grupo Sur, el cual expresa los intereses políticos de la "oligarquía porteña". Caracteriza a este grupo como iniciador de una línea epígona en la literatura argentina respecto de los movimientos europeos, que es alimentada por el ejercicio institucionalizado de la traducción. Opone a este oficialismo cultural, movimientos poéticos como el invencionismo y el surrealismo, surgidos en los años cincuenta y sesenta, que desarrollan hacia Sur una actitud crítica y de enfrentamiento. Luego afirma que esa oposición al oficialismo se irá profundizando hasta hacer visible que el enfrentamiento con la elite cultural supone el conflicto con sus posiciones ideológicas. En esa línea declara que oponerse a ese oficialismo en el terreno estético y político implica "no publicar en La Nación y enfrentar a la clase que domina y entrega al país" (Walsh, Urondo y Portantiero: 1994 (1969): 48). Walsh, acuerda en incluir en esa delimitación del oficialismo literario a La Nación, al que caracteriza como el diario de la "oligarquía terrateniente". Del mismo modo, coincide con Urondo en que Sur se "adueñó del campo cultural” durante el peronismo, y ése fue uno de los resortes que luego le permitió derrocar a Perón. En lo relativo al panorama de la narrativa, Walsh juzga que Arlt constituye uno de los polos válidos para cualquier narrador argentino, y observa que Borges representa el polo opuesto. Ambos "polarizan las dos tendencias, las dos actitudes de la lucha de clases en un poeta" (Walsh, Urondo y Portantiero: 1994 (1969): 45). Finalmente, Walsh y Urondo coinciden en indicar el "fracaso del frondizismo" como el momento a partir del cual se produce una crisis que expresa, según ellos, la finalización de la posibilidad reformista en el país y de ese sueño "de integrarse a un gobierno burgués; es decir gente de izquierda integrada a través de un gobierno de tipo burgués, ligeramente progresista". Luego de esa crisis, la idea de una "revolución nacional burguesa se viene abajo completamente" y como corolario "se radicaliza todo el problema en el terreno ideológico, y exige un replanteo (Walsh, Urondo y Portantiero: 1994 (1969): 54).

De regreso a la Argentina, ambos escritores aparecerán convencidos de la toma de partido en pos de la defensa del régimen cubano y afianzarán sus vínculos con el proceso revolucionario. La experiencia de formación e intervención estético-política que significó la participación en el debate político-cultural promovido desde el frente de intelectuales comprometidos con la Revolución Cubana, implicó para Walsh y Urondo una toma de posición ideológica que incorporaba los valores del guevarismo, tanto para el ejercicio de la práctica cultural como para el compromiso militante. La idea de praxis revolucionaria guevarista encarna en Walsh y Urondo a través de dos principios fundamentales: la convicción de que la necesidad ética de modificar la realidad obliga al compromiso directo y a la entrega revolucionaria; y el planteo político de que la lucha por la emancipación de los pueblos oprimidos tiene un instrumento fundamental, que es la lucha armada (Redondo, 2001: 115). Así, su compromiso con Cuba y sus 
Fabiana Grasselli. La escritura testimonial...

concepciones guevaristas quedarán evidenciados en las intervenciones que ambos escritores realizarán frente al Caso Padilla.

Algún tiempo antes de este episodio, Walsh había respondido a un texto que el escritor Cabrera Infante publicara en la revista Primera Plana en contra de Fidel Castro, denunciando -entre otras cosasque "en Cuba no se podía escribir". Walsh le contesta por medio de una carta que envía a dicha revista ${ }^{4}$, probando hasta qué punto -señala Jozami- "había adoptado una postura militante en defensa del proceso cubano". En ese texto, el escritor define claramente los dos argumentos centrales que desarrollará a partir de entonces con respecto a la relación de los intelectuales latinoamericanos con Cuba y con la militancia revolucionaria: por un lado, la idea de que los errores, injusticias y aspectos criticables del proceso cubano no pueden parangonarse con el significado épico de la lucha de liberación, y por otro, la consideración de que los escritores y artistas deben preguntarse por el sentido de una obra literaria que no dé cuenta de los procesos revolucionarios (Jozami, 2006: 122).

En noviembre de 1968 se conoce la noticia de que el escritor Heberto Padilla fue encarcelado al ser denunciado por las fuerzas armadas cubanas por presuntas maniobras contrarrevolucionarias. Según un testimonio de Noé Jitrik, recogido por Pablo Montanaro “cuando se plantea la decisión de cárcel para Padilla nos reunimos en la casa de Walsh para conversar sobre el tema con Ricardo Piglia, Urondo, Rozitchner, David Viñas, Héctor Schmucler y alguna otra gente que había estado en Cuba"5 (Montanaro, 2003: 81). Como respuesta, Rodolfo Walsh publica una nota en el diario La Opinión, titulada "Ofuscaciones, equívocos y fantasías en el mal llamado Caso Padilla". Como indica Jozami, ese artículo responde a la necesidad de desarmar lo que considera una maniobra para desprestigiar a la revolución. Por eso, en el texto desacredita las acusaciones de que Padilla haya sido torturado y muestra como desmesurados los argumentos que sostienen la comparación entre el caso cubano y el estalinismo, todo con un tono de cuestionamiento a los intelectuales europeos o residentes en Europa, quienes habían firmado una carta dirigida a Fidel Castro en repudio al hecho (Jozami, 2006: 125). Esto no significa que Walsh desconociera los aspectos indefendibles de la situación cubana, lo cual, como también señala Jozami, pueden leerse en las entrelíneas de los textos mencionados (Jozami, 2006: 123). No obstante, al igual que Urondo y que muchos otros intelectuales de toda América Latina, que se definían revolucionarios y apoyaban a Cuba, considera preferible silenciar esas críticas antes que hacer públicos

\footnotetext{
${ }^{4}$ Las declaraciones de Cabrera Infante, en Primera Plana, No 292, 30 de julio de 1968. La respuesta de Walsh, “Exiliados”, se publica como carta en la misma revista, el 20 de agosto de 1968.

${ }^{5}$ Respecto de este episodio, Walsh anota en su diario el 29 de mayo de 1971: “Eso se vio a raíz del caso Padilla. Aparentemente yo dije y ordené lo que muchos querían decir (...) El caso Padilla de todas maneras nos ha agitado, nos ha sacudido, nos ha acercado y alejado. Cuando la primera ola rompió aquí, nuestros amigos se habían reunido para mandar a La Habana una carta o un cable. Pude desarmar eso en media hora, con media docena de preguntas. Pero es notable que esas preguntas no se les hubieran ocurrido" (Walsh, 2007a (1971): 207).
} 
sus desacuerdos con algunos aspectos de la revolución (Montanaro, 2003: 80-81). A propósito de esta situación, en la novela de Urondo, Los pasos previos, existe un diálogo entre dos personajes, que sintetiza la mirada del escritor ante lo que consideraba, junto con Walsh, una excusa de algunos intelectuales para romper con Cuba:

- ¿La línea de los intelectuales latinoamericanos, cuál será?

- No hay una línea; hay dos. Una, encuadrarlos dentro de la lucha revolucionaria.

- ¿De qué manera, como combatientes?

- Eso es cosa de cada uno.

(...)

- ¿Cuál es la otra línea?

- Declaracionista, manifestarse revolucionarios, pero defender ideas como libertad de expresión, el sagrado derecho de la negatividad. El deber de la crítica.

- No simplifiques.

- Dejáme de jorobar, todos estos tipos parecen intelectuales europeos que ven el stalinismo por todas partes (Urondo, 2000 (1972): 146-147).

\subsection{Un programa compartido: militancia intelectual y literatura testimonial}

En virtud de los cruces identificados en las trayectorias vitales, políticas e intelectuales de Walsh y Urondo hacia fines de la década del sesenta, he considerado el tiempo cercano al año 1968 como el hito de un trayecto compartido en el que condensan los entrelazamientos que pueden rastrearse en sus itinerarios. Así pues, para hacer visibles estos anudamientos en el plano de los recorridos vitales, resulta pertinente un testimonio de Lilia Ferreyra, recopilado por Enrique Arrosagaray en su libro Rodolfo Walsh, de dramaturgo a guerrillero, en el cual se hace referencia a la relación de amistad que se había consolidado entre los escritores hacia 1968:

Rodolfo (...) tenía una relación frecuente con amigos cuando tenía con ellos algún proyecto en común, algún trabajo o algo que los uniera. Rodolfo no era un hombre muy sociable. No era de invitar a su casa. Rogelio [García Lupo] era más sociable; pero por ejemplo el amigo con el que se encontraban a tomar un café sin necesidad de que hubiera asuntos de trabajo, era Paco Urondo (Arrosagaray, 2006:28).

En consonancia con esta lectura de sus itinerarios, pueden interpretarse una serie de declaraciones paradigmáticas, de y sobre los autores, en relación a las similitudes y entrecruzamientos de sus biografías intelectuales. Dichas declaraciones dan cuenta de que ambos comparten un momento de inflexión en sus recorridos hacia 1968, en el cual se evidencia una rearticulación de la relación entre política y escritura. En este sentido son elocuentes algunas anotaciones del diario de Rodolfo Walsh, y 
Fabiana Grasselli. La escritura testimonial...

declaraciones en una entrevista que le realizaron para La Opinión Cultural en 1972, en las cuales desarrolla los siguientes planteos:

Muy bien, todavía querés ser un escritor. ¿Dejaste de serlo en 1969, cuando publicaste Rosendo, o en 1967, después de Un kilo de oro? (...) A decir verdad mis hábitos empezaron a desvanecerse en 1967, cuando encaré la novela. Ese año sólo terminé un cuento.

Pero las cosas cambiaron realmente en 1968, cuando la política lo ocupó todo. Entonces empecé a ser un escritor político (Walsh, 2007a (1971): 206).

Mi relación con la literatura se da en dos etapas: de sobrevaloración y mitificación hasta 1967, cuando ya tengo publicados dos libros de cuentos y empezada una novela; de desvalorización y paulatino rechazo a partir de 1968, cuando la tarea política se vuelve una alternativa.

La línea de Operación Masacre era una excepción: no estaba concebida como literatura, ni fue recibida como tal, sino como periodismo, testimonio. Volví a eso con Rosendo, porque encajaba con la nueva militancia política (Walsh, 2007a (1972): 234).

Con un significado similar existe un testimonio de Jitrik, recogido por Pablo Montanaro, en el que reconoce que los viajes a Cuba entre 1967 y 1968 "deben haber producido algún cambio en Paco, en el sentido de una mayor politización que la que había tenido hasta ese entonces” (Montanaro, 2003: 74). Igualmente, en la ya citada entrevista que le realizó Marcelo Pichón Riviére a Urondo, en 1971, se hace referencia a la producción del poeta en los años inmediatamente anteriores. Entonces, Urondo manifiesta lo siguiente:

En la vida, se sea o no poeta, se trata de ir reuniendo las cosas de uno, hasta las más dispares señala Paco-. Al principio, por supuesto, fue algo de lo que yo no era consciente; después, en forma premeditada, fui dando un orden a todo lo que estaba dentro de mí. La política, por ejemplo, que me importó desde chico y que durante tanto tiempo estuvo escindida de mi obra (Pichón Riviére, 1971: 38).

Para continuar con la similitudes que presentan ciertas búsquedas, opciones y modos de encarar la tarea intelectual en Walsh y Urondo, entre 1970 y 1974, período de gran aceleración de los procesos socio-políticos y de profundo involucramiento de estos escritores en la lucha armada, ambos producen una constelación de textos que podrían definirse como programáticos: una entrevista que le realizaron a Walsh en 1971 para la revista Nuevo Hombre, el ensayo “Algunas reflexiones” de Francisco Urondo publicado en el número 17 de Crisis, en 1974; la recordada entrevista realizada por Ricardo Piglia a Rodolfo Walsh en 1970, y publicada en 1973 con el título "Hoy es imposible en la Argentina hacer literatura desvinculada de la política"; y la ya citada entrevista que Marcelo Pichón Riviére le hizo a Urondo en 1971 para Panorama. En estos textos pueden rastrearse los núcleos de sus concepciones 
Fabiana Grasselli. La escritura testimonial...

acerca de la función del escritor-intelectual y de una literatura revolucionaria en esa singular coyuntura histórica que son los años setentas. Así pues, en ellos son observables ciertas reflexiones, posicionamientos y planteos que permiten reconocer un núcleo ideológico común, o bien, la existencia de postulaciones programáticas compartidas en lo que concierne a la intrincada relación entre práctica militante y escritura literaria expresada en la opción por lo testimonial.

En primer lugar, tanto en Walsh como en Urondo se afianza, en los años setenta, la lectura política de que el país atravesaba una "situación pre-revolucionaria, previa a la lucha definitiva" y como consecuencia de este momento de transición y de crisis de los valores de la cultura dominante, la producción cultural y el campo intelectual se hallaban en proceso de transformación. En este sentido, la noción guevarista del surgimiento del "hombre nuevo", a la que ambos adscribían, les permitió pensar la necesidad de transformación de la subjetividad burguesa del intelectual, a la vez que procesar su autoimagen como intelectuales con todas las contradicciones presentes, pero con la certeza de que con la participación en las luchas del pueblo, en los procesos revolucionarios y en la construcción del socialismo, sobrevendría una nueva identidad intelectual equivalente a ese "hombre nuevo". La convicción de que un nuevo modelo de sociedad produciría hombres diferentes y mejores y nuevas sensibilidades, parece reforzar en ellos el carácter claramente orientado respecto de las aspiraciones colectivas, tanto de las fórmulas estéticas como de las conductas intelectuales. Del mismo modo, los dos escritores identifican como principal obstáculo, en ese proceso de transición, las instituciones intelectuales que promueve la cultura dominante. Éstas deben ser enfrentadas mediante un nuevo modo de trabajo superador de la ideología burguesa y por medio de la contribución a los procesos históricos protagonizados por el pueblo. En este sentido, ambos autores insisten en la idea de que los escritores, artistas e intelectuales revolucionarios deben considerarse trabajadores; mejor dicho, "trabajadores intelectuales", o bien, "trabajadores de las ideologías". Era necesario devenir trabajadores intelectuales, más que integrantes de la institución literaria como ésta había sido definida por la tradición dominante. Así queda planteado por Walsh en una entrevista que le realizaron en 1971 para la revista Nuevo Hombre, y por Urondo en su ensayo “Algunas reflexiones”, publicado en Crisis en 1974:

Ingresé a la CGT de los Argentinos a partir de la serie de artículos de Operación masacre, una campaña periodística que me permitió tomar contacto, a partir del periodismo, con la clase obrera. Yo nunca tuve una vida "intelectual” precisamente y esto te lo digo no porque el término intelectual me suene mal ni mucho menos. Pero antes que todo, fui un trabajador. Mi conversión intelectual es tardía y surge a partir de ciertos libros que escribí.

N.H. ¿Cómo analizarías el paso de un trabajador intelectual desde su posición individualista, reconocida, a una dimensión donde lo importante sea lo colectivo, lo anónimo?

Rodolfo Walsh: Creo que es un paso muy duro, pero nunca más duro que el que da cualquier persona de otro sector social, el obrero y el estudiante, por ejemplo, que abandona su realización 
Fabiana Grasselli. La escritura testimonial...

personal, su posible prestigio para entrar en una acción colectiva. Es un acto de renunciamiento donde se prescinde, en muchos grados de la tarea específica, de la vida en familia. Existe un obstáculo inicial muy grande, que es la propia conformación del intelectual dentro del sistema. Pero ese obstáculo debe franquearse, para poder recibir las otras gratificaciones, las auténticas y mucho más importantes que consisten en vivir, percibir las esperanzas, las inquietudes y los reclamos de la clase obrera, en una elaboración común de sus consignas, de sus caminos de salida. No enseñé nada, ni di cátedra. Fui a aprender mucho y aprendí casi todo. Lo que aporté fue un conocimiento técnico, fundamentalmente. Una tarea formal para hacer llegar con mayor eficacia las ideas, los problemas, a la clase obrera (Walsh, 1971:9).

Los intelectuales y artistas que se aboquen a la construcción de una vanguardia cultural (...) tendrán que luchar contra un enemigo difícilmente identificable. Un enemigo difícil de aislar y de aniquilar. Ese enemigo son ellos mismos. O dicho de otra manera, a estos trabajadores de las ideologías, lo que más les obstaculiza la tarea es la propia ideología (...) Porque allí está el pecado original de intelectuales y artistas: en su práctica y no en su origen de clase. (...) No se ha producido todavía una inmersión de estos grupos en la realidad cabal que se vive en el campo del pueblo. Hay trabas, dificultades objetivas, para esta identificación, y sólo la práctica, la imaginación y la capacidad creativa de estos artistas e intelectuales irán encontrando los caminos, superando las dificultades, hasta que sean suyas las alegrías y las preocupaciones del pueblo. (Urondo, 2009 (1974): 166-167).

Esa identificación entre intelectual y trabajador comporta la puesta en marcha de dos operaciones ideológicas fundamentales para Walsh y Urondo. Por una parte, se enfatiza la idea de que el escritor aporta un saber específico a un proyecto político colectivo, es decir, los "trabajadores intelectuales" contribuyen a los procesos de emancipación con sus habilidades para el manejo de técnicas y con los conocimientos que han adquirido en la conformación de su oficio. Dicha contribución implica la "organicidad" del escritor o intelectual a los sectores populares y trabajadores, y la asunción de sus problemáticas y de sus luchas como propias. Por otra parte, la tarea del intelectual no es impugnada en cuanto tal, sino que es cuestionada cuando se practica dentro de los límites de tolerancia instituidos por la cultura hegemónica. Esta posición, no desemboca en la total depreciación o el abandono de la actividad cultural, sino que más bien propone la búsqueda de una articulación entre escritura y militancia, entre literatura y revolución, entre las armas y las palabras, que pueda contener respuestas o salidas al momento de crisis social, política y cultural. De hecho Urondo sostiene en 1973 que "poética quiere decir acción" y Walsh afirma, en 1970, que no concibe el arte "si no está relacionado directamente con la política, con la situación del momento que se vive en un país" (Walsh, 1994 (1973): 69). 
Fabiana Grasselli. La escritura testimonial...

Ni Walsh ni Urondo plantean que la práctica cultural carezca de validez en sí misma o que deba subordinarse a los dogmatismos y requerimientos de funcionarios. Por el contrario, sus concepciones e intervenciones estético- políticas entrañan la idea de que, si la práctica intelectual es resignificada como trabajo militante en el marco de la lucha de clases, puede desencadenar nuevas formas de producir, de comunicar y hacer circular las producciones artísticas e intelectuales, superando de ese modo "los cánones de la ideología burguesa". En su concepción no se trata de un razonamiento del estilo "medios y fines”, es decir: el trabajo intelectual sólo sería válido como un medio para los fines revolucionarios, sino de una crítica radical de la noción burguesa de la cultura y la política como compartimentos estancos. En este sentido, Walsh y Urondo ensayaron una respuesta afirmativa: debían transformarse, como parte del proceso de transformación social, y convertirse en "trabajadores intelectuales".

Estas concepciones de Walsh y Urondo sobre los nexos entre escritura y práctica política también se articulan en otros dos importantes textos programáticos a través de la validación de la exploración de nuevos géneros y técnicas escriturarias. De manera que, en la entrevista realizada por Piglia a Walsh y el reportaje llevado a cabo por Pichón Riviére a Urondo, encontramos en ambos escritores discursos de legitimación respecto de los valores estéticos y políticos de nuevos formatos y categorías artísticas que privilegian el vínculo con las culturas populares, los aspectos "comunicativos" de los textos, y el conocimiento de la realidad. Concretamente aparece en algunas de sus declaraciones un reconocimiento de la eficacia de los géneros testimoniales. Éstos son valorados como un modo de escritura apropiado para dar cuenta de la experiencia histórica de las fuerzas sociales que luchan por la emancipación de los pueblos, y para rearticular una versión contrahegemónica de los acontecimientos. Frente a la ficción y la novela, Walsh y Urondo oponen la escritura testimonial al reconocerla como una práctica literaria "peligrosa" capaz de desarticular el discurso dominante, dar espacio a las versiones subversivas de la historia y conjurar las voces de los excluidos. Urondo y Walsh hacen referencia a esa legitimación de los relatos testimoniales en los siguientes fragmentos de las entrevistas mencionadas:

Los pasos previos cuenta o intenta contar la historia de algunos héroes anónimos de esa etapa revolucionaria que comienza un poco antes de 1966 y que culmina con el Cordobazo, en el 69. Los personajes son algunos periodistas, que representan el papel de apóstoles, de difusores. Un poco el papel de ellos es el de la novela. Es posible que en ella (...) inserte entrevistas a algunos militantes del peronismo (...) Probablemente no escribiré más ficción; me interesa ahora hacer libros testimoniales, porque la realidad que vivimos me parece tan dinámica que la prefiero a toda ficción. Y seguiré escribiendo poemas: una especie de fatalidad (Pichón Rivière, 1971:38).

Habría que ver hasta qué punto el cuento, la ficción y la novela no son de por sí el arte literario correspondiente a una determinada clase social en un determinado período de desarrollo, y en ese sentido y solamente en ese sentido es probable que el arte de ficción esté alcanzando su 
Fabiana Grasselli. La escritura testimonial...

esplendoroso final, esplendoroso como todos los finales, en el sentido probable de que un nuevo tipo de sociedad y nuevas formas de producción exijan un nuevo tipo de arte más documental, mucho más atenido a lo que es mostrable. Eso me preguntaron, me hicieron la pregunta cuando apareció el libro de Rosendo. Un periodista me preguntó por qué no había hecho una novela con eso, que era un tema formidable para una novela. Lo que evidentemente escondía la noción de que una novela con ese tema es mejor o es una categoría superior a la de una denuncia con ese tema. Yo creo que esa concepción es una concepción típicamente burguesa, de la burguesía y ¿por qué? Porque evidentemente la denuncia traducida al arte de la novela se vuelve inofensiva, no molesta para nada, es decir, se sacraliza como arte (...) creo que gente más joven que se forma en sociedades distintas, en sociedades no capitalistas o en sociedades que están en proceso de revolución, gente más joven va a aceptar con más facilidad la idea de que el testimonio y la denuncia son categorías artísticas por lo menos equivalentes y merecedoras de los mismos trabajos y esfuerzos que se le dedican a la ficción (Walsh, 1994 (1973): 67-68).

En esa atmósfera se inscriben las conceptualizaciones y escrituras testimoniales de Walsh y Urondo. Ambos se alejan tanto de las propuestas vanguardistas de los escritores del boom, que rechazan el "referente", como del realismo social y directo sostenido por los comunistas dogmáticos. Consideran el testimonio como una forma de relato que vendría a superar a la novela en tanto género identificado con la cultura burguesa, a la vez que le reconocen una capacidad para encauzar la denuncia, articular las narraciones de las memorias populares, incorporar el documento y dar cuenta de la dinámica social. La propuesta de Walsh y Urondo no sólo considera la utilización de nuevas técnicas o la implementación de nuevos recursos del lenguaje, sino que busca la transformación radical del discurso literario, asumido como praxis.

Esta opción programática de los dos escritores por el relato testimonial no solo habla del anudamiento de sus trayectorias y sus estrategias escriturales, sino que da cuenta de la búsqueda compartida de respuestas frente a las preocupaciones de quienes asumían la práctica literaria como compromiso militante.

Walsh y Urondo supieron de la importancia que adquirió para la intelectualidad cubana el texto de Miguel Barnet, Biografía de un cimarrón (1966) (Walsh, 1994 (1973): 68), o relatos testimoniales, como La noche de Tlatelolco (1971) de Elena Poniatowska, en los cuales se denuncia el terrorismo de Estado y la violencia represiva en América Latina. Además, en 1970, Casa de las Américas impulsa el cultivo del testimonio al publicar en la revista una caracterización específica del género y al establecer el Premio Anual a esta modalidad literaria. Rodolfo Walsh es convocado como jurado ${ }^{6}$ y responde que considera "un gran acierto de Casa de las Américas haber incorporado el género testimonio al concurso

\footnotetext{
${ }^{6}$ La obra ganadora en ese primer concurso de 1970 fue La guerrilla tupamara, de María Esther Giglio.
} 
anual" porque constituye "la primera legitimación de un medio de gran eficacia para la comunicación popular" (Casa de las Américas, № 200, 1995: 121). De esta manera, se comienza a postular desde esta institución la necesidad de hallar nuevos registros discursivos capaces de oponer al deterioro de los canales tradicionalmente destinados a la difusión de la cultura, nuevas vías y procedimientos innovadores para transmitir conocimiento y para la expresión artística. En este sentido, Urondo y Walsh contribuyeron con su escritura a la consolidación de lo que se denominaba novela-testimonio o testimonio a secas, convencidos de que en este género primaba la experiencia de la realidad social a la cual se imprimía un sentido fundamentalmente histórico.

Por otro lado, esta praxis escritural supuso para los escritores una toma de posición frente a la literatura como institución, una suerte de declaración política y estética acerca de la literatura y sus límites. No se trata simplemente de un cambio temático (la realidad de las persecuciones del pueblo, el sufrimiento del pueblo), sino en una instancia de transformación formal. Desafiaron así la idea de que la literatura posea alguna propiedad esencial que la distinga, en favor de una concepción de lo artístico como una práctica sujeta a condiciones históricas, a los límites y presiones de las instituciones y la lucha de clases, a los avatares de la propia subjetividad y sus fragilidades. De allí la convicción acerca de las posibilidades de una escritura testimonial que puede empuñarse como un arma en varios sentidos: como discurso develador del carácter histórico del conflicto entre la clase trabajadora y las clases dominantes; como una reconstrucción del pasado reciente, desde la perspectiva de los dominados, que confronta con las historias oficiales barriendo a contrapelo la historia, como un modo discursivo que activa en sus lectores la comprensión política y la intervención sobre la realidad histórica, como escritura estético-política capaz de cuestionar los conceptos institucionalizados acerca de lo qué es lo literario, subvirtiendo esa ideología inmovilizante acerca de la literatura como un compartimento estanco. En esa reposición de lo que no es inmediatamente percibido, los textos testimoniales aparecen como una práctica crítica que revela aspectos expresamente ocultados por "los dueños de todas las cosas", al decir de Walsh. Así, las apuestas estético-políticas de Walsh y Urondo operaron en dirección al rebasamiento de los límites del arte burgués contemplativo, sacralizado.

\section{Algunas consideraciones finales}

El momento histórico constituido por los años 1968-1969 representa un clivaje luego del cual se profundiza la politización del campo intelectual y se evidencia un borramiento de los límites entre

práctica política y práctica intelectual. Esta radicalización se acentuó a partir del Cordobazo, cuando la situación desembocó en la combinación de una crisis de acumulación y una crisis de hegemonía que venía gestándose desde inicios de la década. 
Este ritmo vertiginoso del tiempo histórico, en una época marcada por el espíritu revolucionario, dejó su huella en la aceleración de las trayectorias personales, políticas y artísticas de Rodolfo Walsh y Francisco Urondo, para quienes la inminencia de la crisis revolucionaria y la necesidad del combate con la burguesía en el plano cultural y político precipitaría en la militancia dentro de organizaciones políticomilitares y en la búsqueda de modos de politización de la práctica escritural. Las experiencias, los saberes, las herramientas que fueron adquiriendo en la configuración de su oficio de escritores y periodistas confluirían con sus experiencias como intelectuales y militantes puestos al servicio de proyectos revolucionarios. De este modo, en el tiempo cercano a 1968, sus trayectorias, que hasta ese momento habían tenido algunos puntos de contacto a partir de ciertas fraternidades ideológicas, de la colaboración en Prensa Latina y del encuentro en los ambientes del periodismo (Leoplán, Panorama, La Opinión) se entrelazarían y condensarían en un proyecto escritural fundamental, la práctica de los géneros testimoniales.

Es probable que esta coincidencia de Walsh y Urondo en las opciones literarias, en la valoración y el ejercicio de la escritura testimonial como elemento fundamental de sus elecciones programáticas, pueda pensarse como el correlato de la confluencia de sus trayectorias intelectuales y políticas: la militancia conjunta, la reflexión compartida en torno a los tópicos fundamentales de los escritores comprometidos de la época, y la colocación de ambos en la franja del campo intelectual que, luego de 1968, ratificó sus vínculos con la Revolución Cubana y asumió las responsabilidades del intelectual revolucionario.

En este sentido, resulta interesante observar que previamente a este momento de concurrencia en los recorridos de nuestros escritores, Walsh había sido autor de importantes relatos testimoniales, Operación Masacre y ¿Quién mató a Rosendo?, pero no los consideraba textos literarios, sino escritos periodísticos (Walsh, 2007 (1972): 234). Será hacia principios de la década del setenta cuando conceptualice lo testimonial como producción literaria, es decir, como una categoría artística. Urondo hará lo mismo, con la diferencia de que, antes de 1971, no había producido relatos testimoniales: Los pasos previos es de 1972 y La patria fusilada de 1973. Evidentemente, luego de ese momento crucial que constituyen los años 1968/1969, en que la política lo impregnó todo, aparece en los dos escritores un interés estético, ideológico y político por lo testimonial que responde a una búsqueda de formatos desde los cuales se pueda recuperar lo literario y ponerlo al servicio de la revolución. Es un momento de la política, del campo literario y de sus trayectorias en que Walsh y Urondo recuperarán elementos de su oficio de narradores y periodistas para dar lugar a una escritura literaria que destruye las fronteras entre los géneros, entre lo literario y lo no literario, entre el discurso literario y los discursos de la cultura popular. Una escritura literaria que desafía la fragmentación impuesta por la cultura burguesa, que 
Fabiana Grasselli. La escritura testimonial...

articula las versiones contrahegemónicas de la historia y que responde a la crisis de la cultura dominante con la politización del arte. 


\section{Fuentes primarias}

"Responsabilidad del intelectual ante los problemas del mundo subdesarrollado" (1968b), Casa de las Américas, Año 8, o 47, marzo-abril, La Habana.

"Sobre el Congreso Cultural de La Habana. Llamamiento de La Habana" (1968a), Casa de las Américas, Año 8, No 47, marzo-abril, La Habana.

“Tercera declaración del comité de colaboración de la revista Casa de las Américas” fechada el 22 de enero de 1971, Casa de las Américas, Año 36, No 200, julio-septiembre, 1995, La Habana, pp. 118-119.

Pichón Riviére, Marcelo. "Francisco Urondo: La poesía, una especie de fatalidad”. Panorama 218 (1971): 38 .

Urondo, Francisco (1957). "Introducción a la Primera reunión de arte contemporáneo". Santa $\mathrm{Fe}$, Instituto Social-Departamento de acción cultural, Universidad Nacional del Litoral.

Urondo, Francisco (1973). La patria fusilada. Buenos Aires: Ediciones de Crisis.

Urondo, Francisco (2000 [1972]). Los pasos previos. Buenos Aires: Adriana Hidalgo.

Urondo, Francisco (2009 [1974]). “Algunas reflexiones”. Urondo, Francisco (2009) Veinte años de poesía argentina y otros ensayos (incluye ensayos, notas periodísticas, reseñas y entrevistas), Buenos Aires, Mansalva.

Walsh, Rodolfo. “Rodolfo Walsh... desde 1968... desde 1971”. Nuevo Hombre (28/07/1971).

Walsh, Rodolfo (1994 [1973]). "Hoy es imposible en la Argentina hacer literatura desvinculada de la política”. Rodolfo Walsh, vivo. (Baschetti, Roberto, ed.). Buenos Aires: Ediciones de la Flor.

Walsh, Rodolfo (2003 [1969]). ¿Quién mató a Rosendo?, Buenos Aires: Ediciones de la Flor.

Walsh, Rodolfo (2004 [1972]). Operación Masacre, Buenos Aires: Ediciones de la Flor.

Walsh, Rodolfo (2007). El violento oficio de escribir. Obra periodística (1953-1977) (Edición corregida y aumentada a cargo de Daniel Link) Buenos Aires: Ediciones de la Flor. 


\section{Bibliografía}

Alabarces, Pablo (2000). "Walsh: dialogismos y géneros populares". Textos de y sobre Rodolfo Walsh. Lafforgue, Jorge (editor). Buenos Aires- Madrid: Alianza.

Arrosagaray, Enrique (2006). Rodolfo Walsh, de dramaturgo a guerrillero.Buenos Aires: Catálogos

Baschetti, Roberto (1994). Rodolfo Walsh, vivo. Buenos Aires: Ediciones de la Flor.

Bonano, Mariana (2009). "Crítica y poesía. Las intervenciones de Francisco Urondo en las publicaciones periódicas”. Cantar junto al endurecido silencio. Escritos sobre Francisco Urondo. (Gerbaudo, Analía y Falchini, Adriana, edas.) Santa Fe: Universidad Nacional del Litoral.

Falchini, Adriana (2009). "Dejo constancia. Francisco "Paco" Urondo, ese cronista". Cantar junto al endurecido silencio. Escritos sobre Francisco Urondo. (Gerbaudo, Analía y Falchini, Adriana, edas.) Santa Fe: Universidad Nacional del Litoral.

Ferrarotti, Franco (1990). La historia y lo cotidiano. Buenos Aires: Centro Editor de América Latina.

Gerbaudo, Analía y Falchini, Adriana (2009). Cantar junto al endurecido silencio. Escritos sobre Francisco Urondo, Santa Fe: Universidad Nacional del Litoral.

Gilly, Adolfo (1985). La anomalía argentina (Estado, corporaciones y trabajadores). México: Siglo XXI.

Gilman, Claudia (2003). Entre la pluma y el fusil. Debates y dilemas del escritor revolucionario en América Latina. Buenos Aires: Siglo XXI.

Izaguirre, Inés (comp.) (2009). Lucha de clases, guerra civil y genocidio en Argentina 1973-1983: antecedentes, desarrollo, complicidades, Buenos Aires: Eudeba.

Jozami, Eduardo (2004). "Walsh y la "nueva izquierda" de los años '60”. Página/12 (21/03/2004).

Jozami, Eduardo (2006). Rodolfo Walsh. La palabra y la acción. Buenos Aires: Norma.

Longoni, Ana y Mariano Mestman (2000). Del Di Tella a "Tucumán Arde". Vanguardia artística y política en el ' 68 argentino. Buenos Aires: El cielo por asalto.

Mestman, Mariano. “Semanario CGT, Rodolfo Walsh: periodismo y clase obrera”. Causa y Azares 3 (1997).

Montanaro, Pablo (2003). Francisco Urondo. La palabra en acción. Biografía de un poeta y militante, Rosario: Homo Sapiens. 
Pichón Riviére, Marcelo (1971). "Francisco Urondo: La poesía, una especie de fatalidad". Panorama 218 (1971): 38.

Pozzi, Pablo (2004). "Por las sendas argentinas" El PRT-ERP, la guerrilla marxista, Buenos Aires: Imago Mundi.

Pucciarelli, Alfredo (ed.) (1999). La primacía de la política. Lanusse, Perón y la Nueva Izquierda en tiempos del $G A N$. Buenos Aires: Eudeba.

Redondo, Nilda (2001). El compromiso político y la literatura: Rodolfo Walsh. Argentina 1960-1977. Santa Rosa: Amerindia y Universidad de Quilmes.

Redondo, Nilda (2005). Si ustedes lo permiten prefiero seguir viviendo: Urondo, de la guerra y del amor. Buenos Aires: Campana de Palo.

Redondo, Nilda (2005a). "Intelectuales y lucha revolucionaria: Walsh, Conti, Cortázar". Actas del $1^{\circ}$ Congreso Regional del Instituto Internacional Iberoamericana. "Nuevas cartografías críticas: problemas actuales de la Literatura Iberoamericana", Rosario.

Rivera, Jorge (1998). El escritor y la industria cultural. Buenos Aires; Atuel.

Romano, Eduardo (1983). Sobre poesía popular argentina, Buenos Aires: Centro Editor de América Latina.

Tortti, María Cristina (1999). “Protesta social y Nueva Izquierda durante el Gran Acuerdo Nacional”, en La primacía de la política. Lanusse, Perón y la Nueva Izquierda en tiempos del GAN. (Pucciarelli, Alfredo, ed.)Buenos Aires: Eudeba. 